\title{
Influence of Powder Flow Rate on Properties of Laser Deposited Titanium Alloy -Ti6AI4V
}

\author{
Rasheedat M. Mahamood ${ }^{1, a^{*}}$ and Esther T. Akinlabi ${ }^{1}$ \\ ${ }^{1}$ Department of Mechanical Engineering Science, University of Johannesburg, \\ Auckland Park Campus, Johannesburg, South Africa, 2006. \\ amahamoodmr2009@gmail.com
}

Keywords: Additive manufacturing, Laser metal deposition, Microhardness, Microstructure, Powder flow rate

\begin{abstract}
Titanium alloy-Ti6Al4V is an important aerospace alloy with excellent properties but it is classified as difficult to machine material that requires an alternative manufacturing process. Laser metal deposition process is an ideal alternative manufacturing process that can offset most of the problem encountered while processing the alloy using the traditional manufacturing method. Processing parameter play an important role in the resulting properties of material processed using the laser metal deposition process. The key processing parameters that have significant influence in the properties of the processed material in laser metal deposition process include laser power, scanning speed, powder flow rate and gas flow rate. In this study, the effect of powder flow rate on the evolving microstructure and microhardness of Ti6Al4V using the laser metal deposition process is investigated. The laser power, scanning speed and powder flow rate were kept constant while the powder flow rate was varied between $1.44 \mathrm{~g} / \mathrm{min}$ and $7.2 \mathrm{~g} / \mathrm{min}$. The results showed that the microhardness increased as the powder flow rate was increased. The microstructure was found to change from coarse Widmanstätten alpha to coarse martensitic alpha as the powder flow rate was increased. This study is important to know the required powder flow rate to be employed in order to achieve the desired properties during building of new part as well as repair.
\end{abstract}

\section{Introduction}

Laser metal deposition (LMD) process is an advanced manufacturing process that is one of the classes of additive manufacturing technologies capable of producing three dimensional object and repair of high valued parts $[1,2]$. Laser metal deposition process is a contactless manufacturing process that is used for difficult to process materials such as Ti6Al4V [3]. Aerospace industry is in dear need of technology such as LMD process to reduce buy to fly ratio and for repair of high valued components that were not repairable in the past $[4,5]$. The flexibility offered by the LMD process makes it possible to fabricate parts made of composite and functionally graded materials [6-10].

Processing parameters are of great importance in the laser metal deposition process because they affect the resulting microstructure and hence the properties of the deposited materials. A number of studies have been carried out in the literature to understand the influence of processing parameters on the economy and properties of laser metal deposited materials [11-16]. In this study, the influence of powder flow rate on the microstructure and microhardness of laser metal deposited Ti6Al4V. Ti6Al4V is an important aerospace alloy that is widely used because of its excellent properties [17]. Other processing parameters were kept constant and the powder flow rate was varied to understand the effect of this single process parameter on the properties. 


\section{Materials and Methods}

The materials used in this study are the Ti6Al4V powder and substrate. The Ti6Al4V powder is of 99.6\% pure and of particle size analysis of between $150 \mu \mathrm{m}$ and $350 \mu \mathrm{m}$. The substrate is a sheet of $5 \mathrm{~mm}$ thick. The laser used is an Nd: YAG laser of maximum capacity of $4.0 \mathrm{~kW}$. The substrate was sandblasted and rinse using acetone before carrying out the deposition process to remove dirt and aid laser absorption process. The laser power, the scanning speed and the gas flow rate were fixed at $3 \mathrm{~kW}$, $0.05 \mathrm{~m} / \mathrm{s}$ and $2 \mathrm{l} / \mathrm{min}$ respectively. The laser focal length was fixed at a distance of $195 \mathrm{~mm}$ above the substrate to keep the spot size at a constant value of $2 \mathrm{~mm}$. The powder flow rate was varied between $1.44 \mathrm{~g} / \mathrm{min}$ and $7.2 \mathrm{~g} / \mathrm{min}$. The experimental matrix is presented in Table 1 .

Table 1. Experimental Matrix.

\begin{tabular}{|l|l|}
\hline Sample Designation & Powder Flow Rate $(\mathrm{g} / \mathrm{min})$ \\
\hline A & 1.44 \\
\hline B & 2.88 \\
\hline C & 4.32 \\
\hline D & 5.76 \\
\hline E & 7.2 \\
\hline
\end{tabular}

After the deposition process, the deposited samples are sectioned across the deposition direction to reveal the cross section of the samples. The cut samples are mounted in hot resin. The mounted samples are ground and polished following the standard metallurgical preparation of titanium and its alloys [18]. The microhardness was measured on the polished samples using Metkon Vickers hardness indenter with a load of $500 \mathrm{~g}$, dwelling time of $15 \mathrm{~s}$ and distance between indentations maintained at 15 $\mu \mathrm{m}$, following the ASTM standard on microhardness measurement [19]. The polished samples are etched using Knoll reagent and then studied under optical microscope for microstructural extermination.

\section{Results and Discussions}

The results of the microhardness are shown in Table 2. The graph of the average microhardness versus powder flow rate is shown in Figure 1. The microhardness is seen to increase as the powder flow rate was increased. The reason for this can be attributed to the fact that at low powder flow rate, the available laser power was able to completely melt the deposited powder and also created a larger melt pool on the surface of the substrate. The larger melt pool created takes longer to solidify which resulted in the formation of Widmanstätten grains structure (see Figure 2a) which in turn resulted in low microhardness because Widmanstätten grains are softer.

Table 2. Results.

\begin{tabular}{|l|l|l|}
\hline Sample Designation & Powder Flow Rate $(\mathrm{g} / \mathrm{min})$ & Average Microhardness $(\mathrm{HV})$ \\
\hline A & 1.44 & 330.56 \\
\hline B & 2.88 & 367.41 \\
\hline C & 4.32 & 388.02 \\
\hline D & 5.76 & 391.22 \\
\hline E & 7.2 & 392.01 \\
\hline Substrate & - & 300 \\
\hline
\end{tabular}




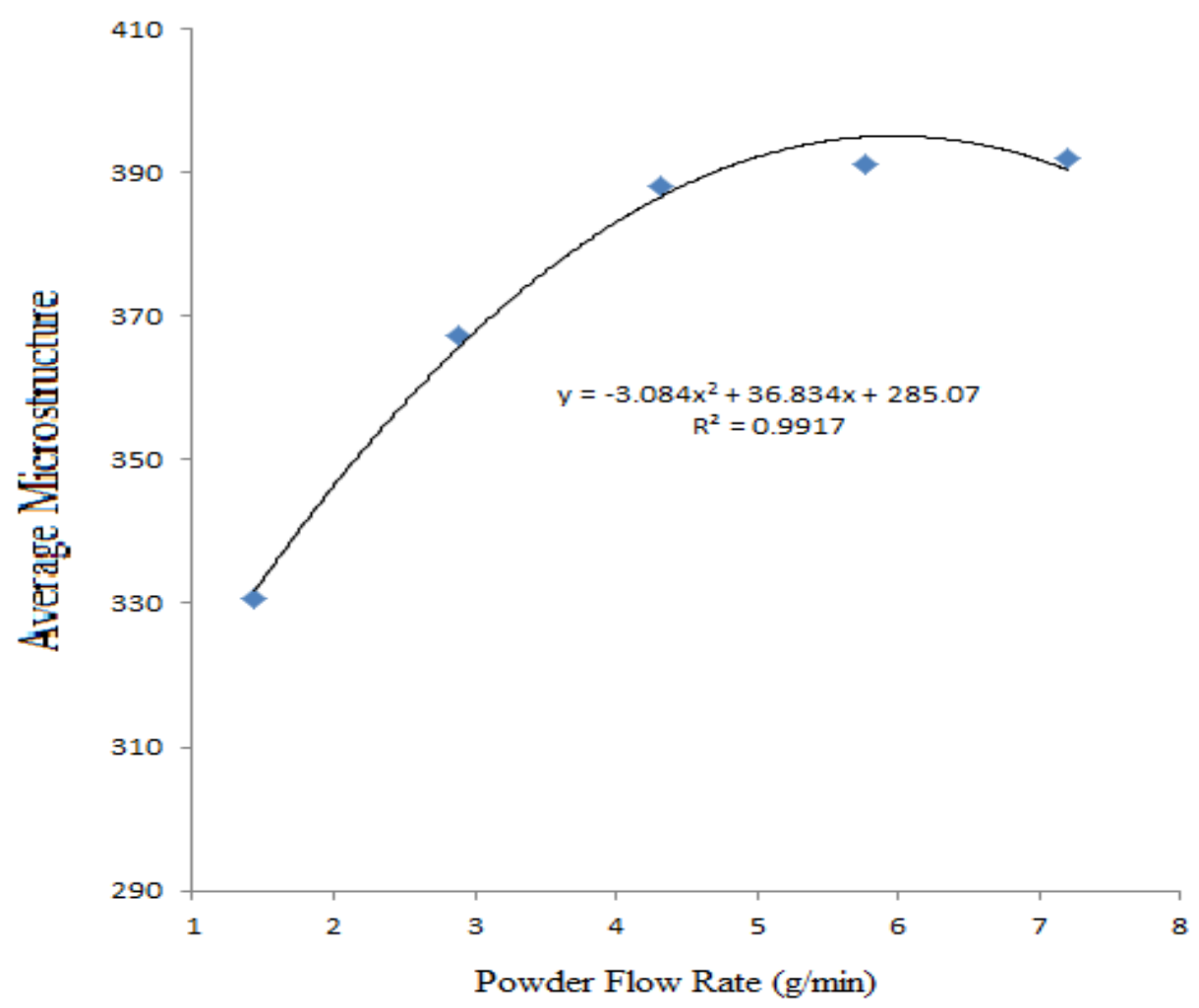

Fig. 1 Graph of microhardness against powder flow rate.

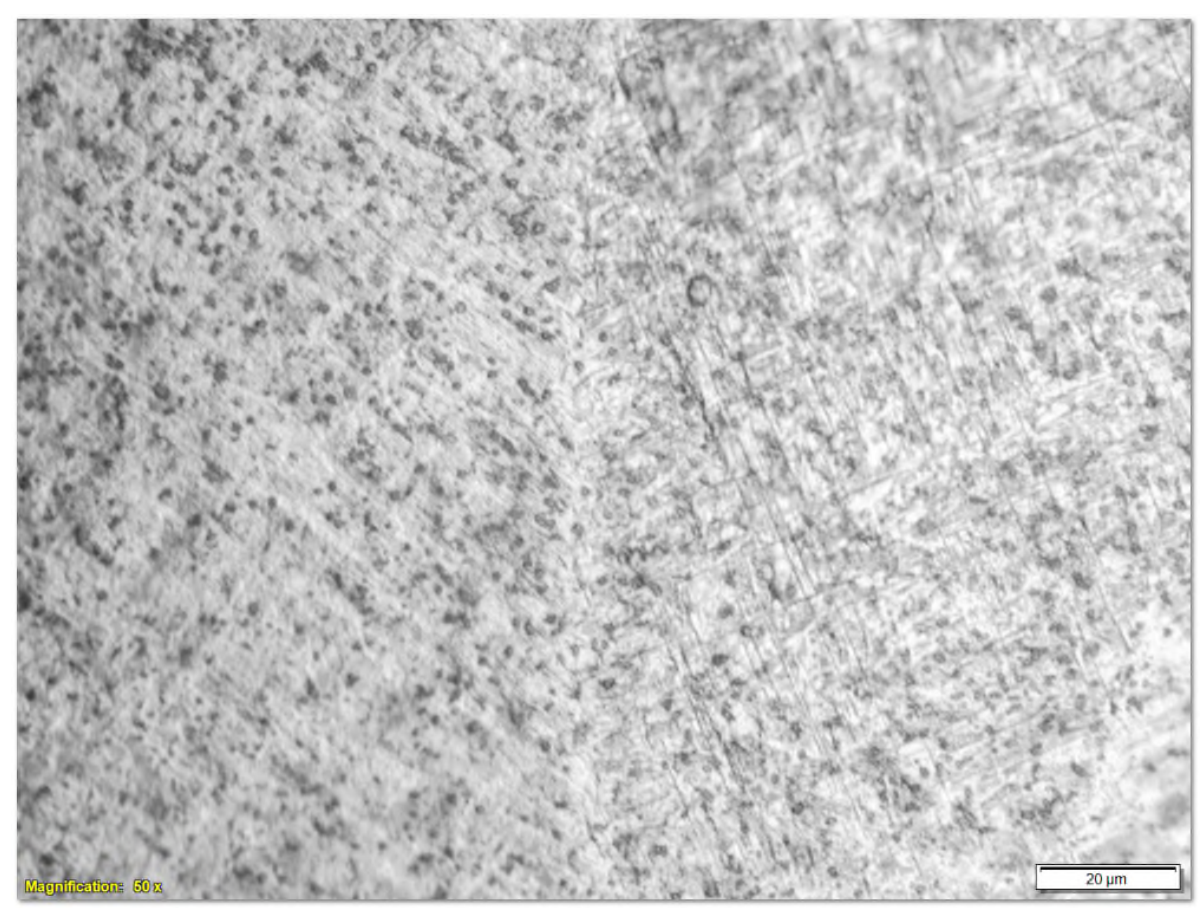

(a) 


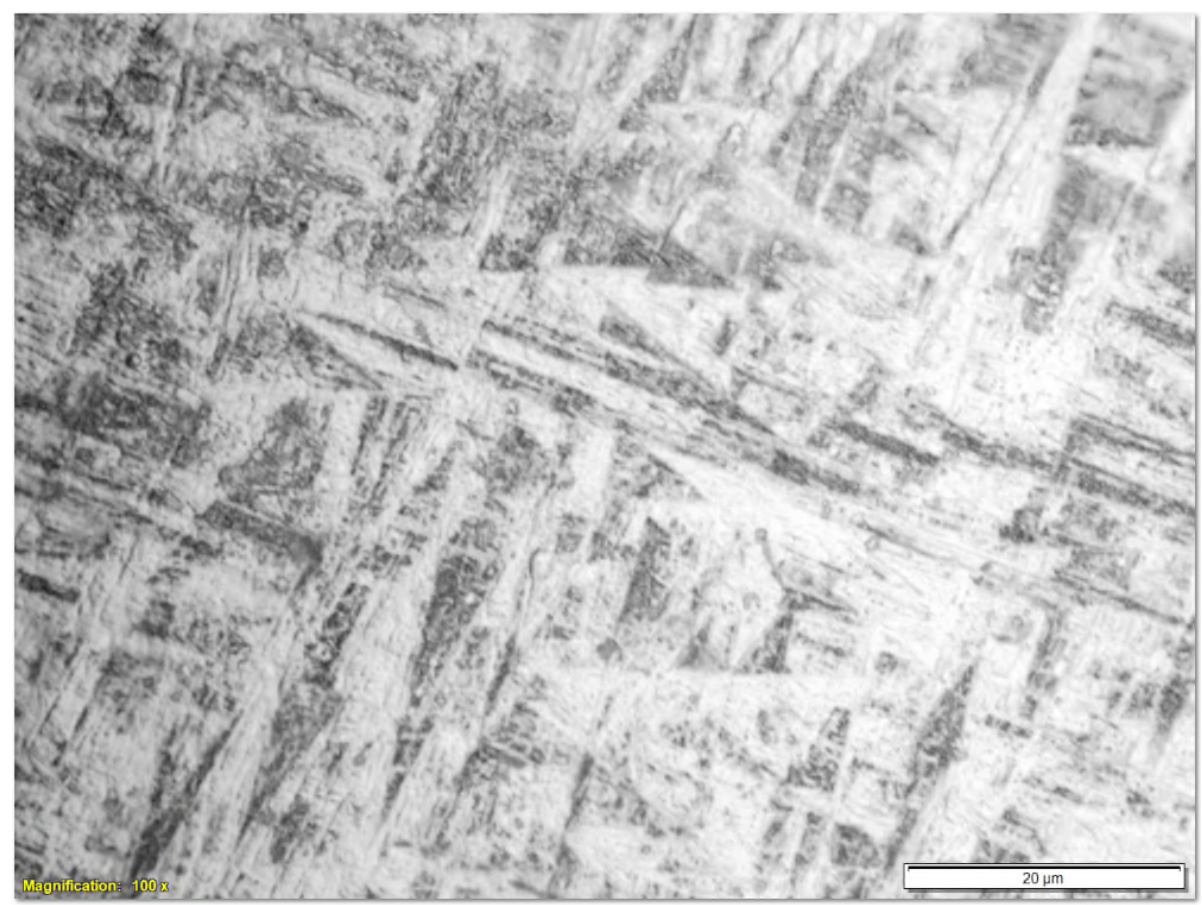

(b)

Fig. 2 Micrograph of sample at powder flow rate of (a) $1.44 \mathrm{~g} / \mathrm{min}$ (b) $5.76 \mathrm{~g} / \mathrm{min}$.

At higher powder flow rate, the delivered powder into the melt pool is more and the available power is largely concentrated on melting the powder with less power to melt the substrate that promotes the formation of melt pool on the substrate. The available laser power quickly melt the powder as it is been delivered and it also quickly solidified resulting in the formation of martensitic microstructure as shown in Fig. 2b. There should be limit to which the powder flow rate should be increased. This is because, if the powder flow rate is increased beyond the capacity of the available laser power, the laser power will not be able fully melt the Ti6Al4V powder and the metallurgical integrity of the deposited sample will be compromised. This could result in improper bonding of the deposit and the substrate.

\section{Conclusion}

The effect of powder flow rate on the evolving properties of laser metal deposited Ti6Al4V has been thoroughly studied in this research work. Ti6A14V is an important aerospace alloy that can easily be processed using the laser metal deposition process. Other processing parameters were kept at constant values while only the powder flow rate was varied. The microhardness was found to increase with increase in powder flow rate. To control the microhardness of the deposited sample, the powder flow rate can be effectively controlled.

\section{Acknowledgement}

This work was supported by University of Johannesburg research council and Rental Pool Grant of the National Laser Centre - Council of Scientific and Industrial Research (NLC-CSIR), Pretoria South Africa. 


\section{References}

[1] R. M. Mahamood, E. T. Akinlabi, M. Shukla, S. Pityana. Revolutionary additive manufacturing: an overview. Laser. Eng. 27(2014) 161-178.

[2] B. Graf, A. Gumenyuk, M. Rethmeier, Laser metal deposition as repair technology for stainless steel and Titanium alloys. Phys. Proc. 39 (2012) 376-381.

[3] Z. M. Wang, E. O. Ezugwu, Titanium alloys and their machinability a review. J. Mater. Proc. Tech. 68 (1997) 262-270.

[4] E. Brandl, V. Michailov, B. Viehweger, C. Leyens, Deposition of Ti-6Al-4V using laser and wire, part I: Microstructural properties of single beads, Surf. Coat. Tech. 206 (2011) 1120-1129.

[5] Y. Wang, H. Zheng, K. Tang, H. Li, S. Gong, TC17 titanium alloy laser melting deposition repair process and properties. Opt. Laser. Tech. 82 (2016) 1-9.

[6] R. M. Mahamood, E. T. Akinlabi, Effect of laser power and powder flow rate on the wear resistance behaviour of laser metal deposited TiC/Ti6Al4V composites, Mater. Today: Proc. 2(4-5) (2015) 2679-2686.

[7] R. M. Mahamood, E. T. Akinlabi, M. Shukla, S. Pityana. Characterization of Laser Deposited Ti6A4V/TiC Composite. Laser. Eng. 29(3-4) (2014) 197-213.

[8] R. M. Mahamood, E. T. Akinlabi, M. Shukla, S. Pityana. Scanning Velocity Influence on Microstructure, Microhardness and Wear Resistance Performance on Laser Deposited Ti6Al4V/TiC Composite. Mater. Des. 50 (2013) 656-666.

[9] R. M. Mahamood, E. T. Akinlabi, M. Shukla, S. Pityana. Functionally graded material: An overview. Proceedings of the World Congress on Engineering, III, WCE 2012, July 4-6, 2012, London, U.K. (2012), pp. 1593-1597.

[10] R. M. Mahamood, E. T. Akinlabi, Laser metal deposition of functionally graded Ti6Al4V/TiC, Mater. Des. 84 (2015) 402-410.

[11] R. M. Mahamood, E. T. Akinlabi, M. Shukla, S. Pityana. Material Efficiency of Laser Metal Deposited Ti6Al4V: Effect of Laser Power. Engineering Letters, 21:1, EL_21_1_03, available online at http://www.engineeringletters.com/issues_v21/issue_1/EL_21_1_03.pdf, (2013).

[12] T. Wang, Y. Y. Zhu, S. Q. Zhang, H. B. Tang, H. M. Wang, Grain morphology evolution behaviour of titanium alloy components during laser melting deposition additive manufacturing, $\mathrm{J}$. Alloy. Comp. (632) (2015) 505-513.

[13] Y. Zhu, X. Tian, J. Li, H. Wang, Microstructure evolution and layer bands of laser melting deposition Ti-6.5Al-3.5Mo-1.5Zr-0.3Si titanium alloy, J. Alloy. Comp. 616 (2014) 468-474.

[14] X. J. Tian, S. Q. Zhang, H. M. Wang, The influences of anneal temperature and cooling rate on microstructure and tensile properties of laser deposited Ti-4Al-1.5Mn titanium alloy, J. Alloy. Comp. 608 (2014) 95-101.

[15] J. Mazumder, L. Song. Advances in Direct Metal Deposition, A laser workshop on Laser Based Manufacturing, University of Michigan, available at http://www.seas.virginia.edu/research/lam/pdfs/ speaker\%20presentations/Mazumder-NSF-IUCRC\%20workshop-2010.pdf, accessed online on 20th March 2017, (2010). 
[16] E. Brandl, V. Michailov, B. Viehweger, C. Leyens, Deposition of Ti-6Al-4V using laser and wire, part I: Microstructural properties of single beads, Surf. Coat. Tech. 206 (2011) 1120-1129.

[17] M. Peters, J. Kumpfert, C. H. Ward, C. Leyens, Titanium Alloys for Aerospace Applications, in: Titanium and Titanium Alloys, Adv. Eng. Mater. 5 (2003) 419-427.

[18] E3-11, Standard Guide for Preparation of Metallographic Specimens, ASTM international Book of Standards, vol. 03.01, (2011).

[19] ASTM E384 - 11e1, Standard Test Method for Knoop and Vickers Hardness of Materials, ASTM International Book of Standards, vol. 03.01, (2011). 